\title{
Componential Analysis of Headgear in English
}

\author{
Haira Rizka \\ hairarizka@ymail.com \\ English Letters Department, IAIN Syekh Nurjati Cirebon
}

\begin{abstract}
This research aims to: (1) classify the hyponym of headgears in English based on their dimensions, (2) examine meaning relations of hyponym and superordinate, and (3) investigate the meaning relations of each co-hyponym. This research employs componential analysis of Kreidler (1998) to examine hyponym components of headgears in English. This is a descriptive qualitative research which describes componential analysis of headgears in English. The data were collected through observation and note taking technique. The collected data were then analyzed by employing textual analysis method. The findings reveal that: (1) 24 hyponyms of headgear are classified into 4 dimensions: wearer, shape, material, and function, and they expose the shared and differentiating features of each hyponym; (2) meaning relation of superordinate can substitute its hyponym, while hyponym cannot substitute its superordinate because the characteristics or features of a hyponym do not include all characteristics or features of a superordinate; (3) meaning relation of co-hyponym is not substitutable because each lexeme (hyponym) has differentiating features and semantic meaning. It is concluded that by employing componential analysis, similar lexemes show their differences.
\end{abstract}

Keywords: componential analysis, headgears, hyponym, superordinate.

\section{Introduction}

All languages, including English, have a discussion related to meaning relation among lexemes. The relation is probably in the form of synonym, antonym, hyponym, or polysemy. The relation, particularly lexemes which have more than one meaning, is sometimes confusing speakers. They frequently compose ambiguous sentences with too general or specific lexemes. One of the strategies to examine the meaning of two lexemes is by understanding the semantic relation of the two lexemes (Kreidler, 1998: 86). For example, in English, the word salary and wage have similarly semantic meaning. However, the two lexemes are used in different situation. Example:

(1.a) My salary as an executive secretary is five million.

(1.b) How much wage do you get for two-hour working?
The two lexemes are used to indicate money paid after working. However, they are used in different conditions. Lexeme "salary" in sentence (1a) is used to indicate money paid for monthly working. On the other hand, lexeme "wage" in sentence (1b) is used to indicate money paid for hourly working. The ability to compose a correct sentence with appropriate words and acceptable meaning can be accomplished by mastering meaning relation of lexemes.

There are two approaches to investigate lexical relation: semantic field theory and truth conditional semantics (Kreidler, 1998: 86). However, this research pays particular attention to examine semantic field theory of headgear in English. Kreidler defines semantic field theory as an attempt to classify lexemes based on their shared and differentiating features (1998: 86). For an instance, "man" and "boy" denote the concept of male human 
in English. These two lexemes have similar components [+human] and [+male]. However, they have differentiating components of "man" as [+adult, -child], while "boy" as [+adult, -child]. This analysis is regarded as componential analysis which differentiates features of each hyponym (Kreidler, 1998: 88). In general, componential analysis assesses to differentiate features of each hyponym.

The term hyponymy is frequently confusing with the term synonym, but the two terms can be basically differentiated by comprehending the two concepts. Hyponym is a condition in which a lexeme possesses all components of other lexemes, while other lexemes do not have all components of a lexeme (Djajasudarma, 1993: 70). For an instance, "helicopter" and "plane" denote 'air transportation' because the two items have shared features [+air] and [+machine]. However, the two items have a clear feature which differentiates each other: "helicopter" is [+propeller], while "plane" is [-propeller]. Therefore, it is palpable that lexical relation of "helicopter" and "plane" is not synonym, but hyponym. To conclude, "helicopter" and "plane" are hyponym of means of transportation, "means of transportation" is the superordinate of "helicopter" and "plane", while, the meaning relations of "helicopter" and "plane" is co-hyponym.

There are 24 lexemes expressing headgears. They have similar components and thus, in several cases, it is difficult to differentiate each lexeme. Consequently, there are some people who denote headgears as "hat". Furthermore, they use the lexeme "hat" interchangeably to denote any type of headgear. In fact, each item of headgears has certain features which differeniate each other. Since the discussion of headgeras in English is interesting, this research aims to: (1) classify the hyponym of headgears in English based on their dimension, (2) examine meaning relations of hyponym and superordinate, and (3) investigate the meaning relations of each cohyponym.

To analyze the features of headgear in English, this research employs componential analysis of Kreidler (1998: 56). Componential analysis is an analysis aimed at determining shared and differentiating features of certain lexemes with co-hyponym. Two lexemes or more probably have shared meaning based on their paradigm. The paradigm shows that lexemes are systematically related (Kreidler,1998: 58). However, differentiating feature(s) shows the paradigm of a lexeme is different from others. When there are one or more unrelated meanings or features, the phenomenon is called as hyponym (Riemer, 2010:135)

Componential analysis enables a research to expose the reflection, shared meaning, and differences of lexemes considered similarly alike (Kreidler, 1998: 105). Many speakers have troubles in mapping information because sometimes they do not use specific word with specific meaning. Therefore, understanding the concept of hyponym, co-hyponym, and superordinate is essential to lead to another concept of componential analysis.

(2.a) There are roses in the vase.

(2.b) There are flowers in the vase.

From the example of entailment above, it is concluded that "rose" is hyponym of "flower". "Flower" is, respectively, the superordinate of rose. Meanwhile, "jasmine", "tulip", and "orchid" are the co-hyponym of "rose".

\section{Methodology}

This is a descriptive qualitative research which describes phenomena of a certain context (Vanderstoep and Johnston, 2009: 35). With this method, the researcher does not have any control on the research variable. Thus, she only reports and describes the phenomena. This research employed semantic approach of Kreidler (1998) which enabled the researcher to investigate componential analysis of headgears in English. Thus, this research could gain different semantic meaning of likely similar lexemes. The data source of this research were corpus of headgears in English. Since this research investigated componential analysis of headgears in English, the data were in the form of pictures.

To collect the data, the researcher employed observation and note taking 
techniques which enabled the researcher to investigate the phenomena (Kesuma, 2007: 43). The collected data were then analyzed by employing textual analysis method. The method was employed to identify and interpret non-verbal signs (Vanderstoep and Johnston, 2009: 210). In this case, non-verbal sign was in the form of pictures of headgear. Furthermore, textual analysis suited the purpose of this research because it enabled the researcher to investigate the perspective of meaning.

\section{Findings and Discussion}

There are 24 lexemes denoting headgear in English and they are called as hyponym of headgear. People frequently refer a kind of headgear as "hat" since they notice some shared features of the item. However, in the real case, each item denoting headgear has differentiating features. Therefore, this research regards this phenomenon as hyponym study and can be analyzed by employing diagnostic meaning of components or smaller-differentiang features (Basiroh, 1992, p.15). Table 1 shows 24 hyponym of headgers in English.

Table 1. Hyponym of Headgear in English

(Source: asypacelearning.com)

\begin{tabular}{|c|c|c|c|}
\hline No. & Lexeme & Picture & Description \\
\hline & Balaclava & & $\begin{array}{l}\text { Made of soft fabric, usually wool, with } \\
\text { flexible shape. Worn to fully cover head, } \\
\text { face, and neck. }\end{array}$ \\
\hline & Beret & & $\begin{array}{l}\text { A round, flat, and deflated headgear, } \\
\text { usually made of soft fabric, and worn as } \\
\text { an accessory or perfect performance. }\end{array}$ \\
\hline & Bonnet & & $\begin{array}{l}\text { A round hat with wide and stiff brim, } \\
\text { covering head and ears and tied by a } \\
\text { fabric string under the chin. }\end{array}$ \\
\hline & Bobble hat & & $\begin{array}{l}\text { A cone hat with round shape, made of wool } \\
\text { with a small round ball above the } \\
\text { headgear, and worn to give warmth. }\end{array}$ \\
\hline & Bowler hat & & $\begin{array}{l}\text { A black headgear of male with rounded } \\
\text { crown and hard felt fabric resembling a } \\
\text { bowl, and worn to perfect performance. }\end{array}$ \\
\hline & Cap & & $\begin{array}{l}\text { Soft headgear with a rounded crown and a } \\
\text { stiff peak projecting in front. Worn to } \\
\text { protect from the sun or perfect } \\
\text { performance. }\end{array}$ \\
\hline
\end{tabular}




\begin{tabular}{|c|c|}
\hline Cloche & $\begin{array}{l}\text { Resembling a chime with stripes and } \\
\text { rolled brim ad worn by women }\end{array}$ \\
\hline Fascinator & $\begin{array}{l}\text { Fully decorated with flowers or lace. This } \\
\text { headgear does not fully cover head and } \\
\text { thus, needle is needed to put it on the } \\
\text { head. Worn to decorate head and perfect } \\
\text { performance. }\end{array}$ \\
\hline Fez & $\begin{array}{l}\text { Resembling a tube, a close-fitting skull } \\
\text { cup, and short cylindrical peakless hat } \\
\text { made of hard fabric with a tassel attached } \\
\text { on the top of the hat. Worn to perfect } \\
\text { performance. }\end{array}$ \\
\hline Flat cap & $\begin{array}{l}\text { Rounded cap with small stiff brim in front } \\
\text { and a bit higher on the top. Made of stiff } \\
\text { fabric and worn to perfect performance. }\end{array}$ \\
\hline Headscarf & $\begin{array}{l}\text { A square fabric covering most or all of } \\
\text { women's hair and head, remaining the } \\
\text { face uncovered. It is usually worn with } \\
\text { various styles. }\end{array}$ \\
\hline Helmet & $\begin{array}{l}\text { Round headgear. Protective gear made of } \\
\text { hard material and worn to protect head } \\
\text { from injuries. }\end{array}$ \\
\hline Hood & $\begin{array}{l}\text { A triangle hat attaching on a coat or jacket, } \\
\text { worn to cover most head and neck. }\end{array}$ \\
\hline Party hat & $\begin{array}{l}\text { A paper hat resembling a cone and mostly } \\
\text { used at party. }\end{array}$ \\
\hline
\end{tabular}




\begin{tabular}{|c|c|}
\hline Pillbox & $\begin{array}{l}\text { Small hat with a flat crown in one side, } \\
\text { straight upright sides, having no brim, and } \\
\text { suited with the head. }\end{array}$ \\
\hline Straw boater & $\begin{array}{l}\text { Summer hat made of stiff straw with wide } \\
\text { enough brim and flat crown, decorated } \\
\text { with solid or stripped ribbon around the } \\
\text { crown, and worn to protect from sun burn. }\end{array}$ \\
\hline Stetson & $\begin{array}{l}\text { A cowboy's hat with wide brim and usually } \\
\text { made of stiff leather. Worn to protect face } \\
\text { and head from the sun and wind. }\end{array}$ \\
\hline Sombrero & $\begin{array}{l}\text { A Mexican hat with extra wide brim to } \\
\text { protect head, neck, and shoulder from the } \\
\text { sun, tied in a chin string, and having a high } \\
\text { pointed crown. }\end{array}$ \\
\hline Trapper & $\begin{array}{l}\text { A winter hat with earflaps, made of fur, } \\
\text { usually bear, to give warmth, and tied up } \\
\text { to the crown of the cap or fastened at the } \\
\text { chin. Worn to protect head and neck from } \\
\text { cold. }\end{array}$ \\
\hline Trilby & $\begin{array}{l}\text { A narrow brimmed hat with an inside } \\
\text { foldaway in the top crown. Made of stiff } \\
\text { fabric. Worn to perfect performance. }\end{array}$ \\
\hline Turban & $\begin{array}{l}\text { A male headdress, particularly Sikh, } \\
\text { Moslem, and Hindi men. Made of long and } \\
\text { soft fabric. Tied and wrapped on the head. }\end{array}$ \\
\hline Top hat & $\begin{array}{l}\text { An extra-long black or grey hat worn by } \\
\text { men in formal agenda. Made of stiff } \\
\text { material combined with plastic. }\end{array}$ \\
\hline Veil & $\begin{array}{l}\text { A thin and transparent fabric to cover head } \\
\text { and face worn by a bride in wedding } \\
\text { ceremony. }\end{array}$ \\
\hline
\end{tabular}




\begin{tabular}{|l|l|l|}
\hline Visor & $\begin{array}{l}\text { Crownless hat with simple brim and strap } \\
\text { encircling the head and only protecting } \\
\text { face from the sun. }\end{array}$
\end{tabular}

\section{Classifying Headgears Based on the Dimensions}

Co-hyponym relation demands structural hierarchy which classifies lexemes on particular fields (Lyons, 1977: 295). This statement underlies the theory of classifying hyponym based on several dimensions. In general, 24 hyponyms of headgears have 4 dimensions, which each dimension consists of shared and differentiating components or features. Headgear, in general, has dimension of wearer, material, shape and function. Wearer dimension relates to headgear's wearers, material dimension relates to the fabric or material making headgear, shape dimension relates to the shape of head gear, and function dimension relates to function or benefit of wearing headgear.

\section{a. Wearer Dimension}

Wearer dimension has 2 features [women/men]. Some lexemes only have 1 feature, while some other lexemes have 2 features. Based on wearer dimension, the features of each lexeme are as follows:

1) Bonnet, cloche, fascinator, headscarf, pillbox, dan veil [+women, -men].

2) Stetson, sombrero, trilby, turban, top hat, beret, bowler hat, fez, dan flat cap [women, +men].

3) Balaclava, bobble, hat, cap, headscarf, helmet, hood, party hat, straw boater, trapper, and visor [+women, +men].

The above analysis shows that most of headgears with decoration and accessories like flowers, ribbons, or laces are commonly worn by women, while headgears with simple shape and color are worn by men. On the other hand, headgears with crucial and daily function are worn by both sexes.

\section{b. Material Dimension}

Material dimension or the origin of the item has 7 features: [fabric, straw, wool, plastic, paper, leather, fur]. In general, each lexeme has 1 feature, but there are some lexemes which have more than one feature. Based on material dimension, the features of each lexeme are as follow:

1) Beret, bonnet, cap, fascinator, flat, cap, headscarf, pillbox, trilby, turban, veil, and visor [+fabric, -straw, -wool, -plastic, paper, -leather, -fur].

2) Cloche and straw boater [+fabric, +straw, wool, -plastic, -paper, -leather, -fur].

3) Balaclava and bobble hat [-fabric, -straw, +wool, -plastic, -paper, -leather, -fur].

4) Trapper [-fabric, -straw, +wool, -plastic, paper, -leather, +fur].

5) Helmet [-fabric, -straw, -wool, +plastic, paper, -leather, -fur].

6) Party hat [-fabric, -straw, -wool, -plastic, +paper, -leather, -fur].

7) Bowler hat [+fabric, -straw, -wool, +plastic, -paper, -leather, -fur].

8) Fez [+fabric, -straw, +wool, -plastic, paper, -leather, -fur].

9) Hood, Stetson, and sombrero [+fabric, straw, -wool, -plastic, -paper, +leather, fur].

10) Top hat [+fabric, -straw, -wool, +plastic, paper, -leather, -fur].

From the above analysis, it is palpable that the majority of hyponym of headgear has feature [+fabric] because in general, human body wears item made from fabric.

\section{c. Shape Dimension}

Shape dimension has 4 features [round, cone, rectangle, chime]. Several lexemes have only 1 feature, while other lexemes have more than 1 feature. Based on shape 
dimension, the features of each lexeme are as follows:

1) Hood and party hat [-round, +cone, rectangle, -chime].

2) Turban, headscarf, and veil [-round, -cone, +rectangle, -chime].

3) Cloche [+round, -cone, -rectangle, +chime].

4) Sombrero [+round, +cone, -rectangle, chime].

5) Trapper [+round, -cone, +rectangle, chime].

6) Balaclava, beret, bonnet, bobble hat, bowler hat, cap, fascinator, fez, flat cap, headscarf, helmet, pillbox, straw boater, stetson, trilby, top hat, and visor [+round, -cone, rectangle, -chime].

The above analysis indicates that most of hyponym of headgears have feature [+round] because the shape of headgear adjusts the shape of head. As the result, headgear is comfortably worn.

\section{d. Function Dimension}

Each model of headgears is worn for multiple functions and needs. Therefore, from function dimension, hyponyms of headgear have 5 features [protection from the sun, protection from cold, head protection, neck protection, accessory]. Some lexemes only have 1 feature while some others have more than 2 features. Based on function dimension, the features of each lexeme are as follow:

1) Cap, visor, straw boater, and Stetson [+protection from the sun, -protection from cold, -head protection, -neck protection, -accessory].

2) Hood, balaclava, and trapper [-protection from the sun, +protection from cold, thead protection, +neck protection, accessory].

3) Helmet [-protection from the sun, protection from cold, +head protection, neck protection, -accessory].

4) Beret, bowler hat, cloche, fascinator, fez, flat cap, headscarf, party hat, pillbox, trilby, turban, top hat, and veil [-protection from the sun, -protection from cold, -head protection, -neck protection, +accessory].
5) Bonnet and bobble hat [-protection from the sun, +protection from cold, -head protection, -neck protection, +accessory].

6) Sombrero [+protection from the sun, protection from cold, -head protection, neck protection, +accessory].

\section{Meaning Relations between Hyponym and its Superordinate}

There are 24 hyponyms of headgears. Each lexeme has shared and differentiating features. Superordinate have all characteristics of all hyponyms of headgears. On the other hand, each hyponym of headgears does not have all characteristic of the superordinate. The linguistic phenomenon occurs because hyponym is part of superordinate.

(3.a) People wear a in winter.

(3.b) People wear a headgear in winter.

(3.b) People wear a trapper in winter.

Sentence (3a) needs a lexeme which can complete the sentence, and "headgear" can complete the sentence as shown by sentence (3b). The same case also occurs in sentence (3c). Contextually, sentence (3b) is acceptable in meaning and can be substituted by "trapper". Contextually, the features of "trapper" can complete the sentence [+men, +women, +wool, +fur, +protection from cold]. Sentence (3c) with the use of hyponym is more informative than sentence (3b) with the use of superordinate. Furthermore, the ideas and information brought by sentence (3c) is more specific than sentence (3b). Interlocutor will easily comprehend the information because sentence (3c) focuses on a particular object.

(4.a) A bride wears on her head in wedding ceremony.

(4.b) A bride wears headgear on her head in wedding ceremony.

(4.c) A bride wears pillbox on her head in wedding ceremony.

Sentence (4a) can be completed with the word "headgear" as shown in example (4b). Sentence (4b) with "headgear" is considered acceptable and correct because a bride 
possibly wears a headgear. However, sentence (4b) is less informative because there are many types of "headgear". Interlocutor is probably confused when a speaker brings too general information and hardly maps the ideas. On the other hand, sentence (4c) brings more informative sentence with the use of "pillbox". "Pillbox" can substitute "headgear" because it has particular features [+men, +fabric, +round, +accessories] which fit to complete the information. Another reason for selecting "pillbox" is due to its particulate function worn by a bride in a wedding ceremony.

From the two previous examples, it can be concluded that lexical meaning of superordinate can substitute its hyponym with appropriate context of a sentence. Information completed with superordinate brings less informative ideas than that with hyponym. An interlocutor can easily map the information and specify the idea when the sentence is modified with hyponym because it has specific features owned by a lexeme. On the other hand, superordinate has broad features which possibly creates confusion and misinterpretation. Particular hyponym cannot substitute superordinate because a hyponym only has several features of superordinate. Therefore, all hyponyms must complete a sentence to substitute a proper superordinate.

(5.a) is worn on head.

(5.b) Headgear is worn on head.

(5.c) Straw boater is worn on head.

Sentence (5a) is properly completed with "headgear", as shown in example (5b), because all types of headgears (hyponym) are worn on head. Meanwhile, when the sentence is completed with specific lexeme the information is not properly accepted, and thus, some information is missing. This phenomenon is shown in example (5c). "Straw boater" gives narrow information because it is not only "straw boater" worn on head, but also some other types of headgears such as "headscarf, helmet, pillbox", or "stetson". Therefore, "straw boater" (hyponym) is less proper to substitute "headgear" (superordinate).

\section{Meaning Relations among Co- hyponym}

There are 24 lexemes expressing "headgear" in English. They are "balaclava, beret, bonnet, bobble hat, bowler hat, cap, cloche, fascinator, fez, flat cap, headscarf, headscarf, helmet, hood, party hat, pillbox, straw boater, stetson, sombrero, trapper, trilby, turban, top hat, veil", and "visor". They are the hyponyms of "headgear". Thus, the relation between "beret", and the other types, with "headgear" is co-hyponym.

Lyons posits that hyponym of superordinate always compares 'sense' or features owned (1977: 294). Furthermore, each hyponym compares shared and differentiating features to indicate distinctiveness of a lexeme. Meaning relations of co-hyponym results in slightly complicated concept of meaning because each lexeme has more specific feature which distinguishes them. However, componential analysis enables a linguist to investigate that two slightly similar lexemes have differentiating features.

(6.a) A cowboy wears to protect him from the sun.

(6.b) A cowboy wears steson to protect him from the sun.

(6.c) A cowboy wears sombrero to protect him from the sun.

To complete sentence (6a), a lexeme with particular and proper lexeme is needed. "Stetson" in example (6b) is the correct answer because it has features which suit the context of sentence. A "Stetson" is commonly worn by a cowboy because its features are [+men, +fabric, +leather, +round, + protection from the sun, -accessory]. "Stetson" is worn by a cowboy to protect him from the sun, particularly when he is in the field. Furthermore, the brim shape of "Stetson" enables him to easily move and work. On the other hand, example (6c) does create correct sentence because shape dimension, extrawide brim, and function dimension of "sombrero", as accessory, do not fit the context. An extra-wide brim does not enable its wearer to easily move, work, or ride a 
horse because it is heavy. Thus, "sombrero" with the features [+men, +fabric, +leather, +round, +protection from sun, +accessory] does not meet the requirements to correctly complete the context in sentence (6a).

The same case also occurs in example (7a), (7b), and (7c).

(7.a) We wear river by a boat. when we down the

(7.b) We wear straw boater when we down the river by a boat.

(7.c) We wear cap when we down the river by boat.

To complete sentence (7a), a lexeme with proper features is needed. Example (7b) is correct because the features of "straw boater" [+men, +women, + straw, +round, + protection from the sun] meet the requirements with the context of sentence (7a). Since "straw boater" is made of straw and the culture teaches people to wear it, wearing "straw boater" to down a river is appropriately accepted. It enables its wearer to work surround water without worrying being wet. On the other hand, a "cap" which is made of fabric is not appropriately worn to down a river. Thus, example (7c) is less accepted.

The above examples show that meaning relations among co-hyponym cannot be substituted because each lexeme has differentiating features and semantic meaning. By employing componential analysis, similarities and differences of hyponyms are possibly investigated. Furthermore, this analysis enables a linguist to determine the most appropriate lexeme to complete a sentence correctly.

\section{Conclusion and Suggestion}

Componential analysis of headgears in English reveals 4 findings:

1. 24 hyponyms of headgear are classified into 4 dimensions: wearer dimension, shape dimension, material dimension, and function dimension. These 4 dimensions expose the shared and differentiating features of each hyponym.

2. Meaning relation of superordinate can substitute its hyponym. On the other hand, a hyponym cannot substitute its superordinate because the characteristics or features of a hyponym do not include all characteristics or features of a superordinate.

3. Meaning relation of co-hyponym is not substitutable because each lexeme (hyponym) has differentiating features and semantic meaning.

4. By employing componential analysis, similar lexemes show their differences. Shared and differentiating lexemes prove that the 24 lexemes have meaning relation as co-hyponym, and they are the hyponyms of headgear.

Componential analysis is an interesting topic to investigate. A researcher who is interested in investigating similar topic possibly examines componential analysis of particular-linguistic phenomenon in a particular language. There are still multiple linguistic phenomena of unique hyponym and superordinate to investigate. Consequently, the ambiguity of using a language can be minimalized.

\section{References}

Basiroh, Umi. (1992). Telaah Baru dalam Tata Hubungan Leksikal Kehiponiman dan Kemeroniman. tesis). Depok: Universitas Indonesia.

Chaer, Abdul. (2009). Pengantar Semantik Bahasa Indonesia. Jakarta: Rineka Cipta.

Djajasudarma, Fatimah. (2009). Semantik 1: Makna Leksikal dan Gramatikal. Bandung: Refika Aditama.

Kesuma, Tri Mastoyo Jati. (2007). Pengantar (Metode) Penelitian Bahasa. Yogyakarta: Caraswatibooks.

Kreidler, Charles W. (1998). Introducing English Semantics. London: Routledge. 
Lyons, John. (1977). Semantics. Volume 1. Cambridge: Cambridge University Press.

Pateda, Mansoer. (2010). Semantik Leksikal. Jakarta: Rineka Cipta.

Riemer, Nick. (2010). Introducing Semantics. New York: Cambridge University Press.

Saeed, John I. 2009. Semantics. 3rd ed. Oxford: Wiley Blackwell.

Vanderstoep, Scott W. and Deirdre D. Johnston. (2009). Research Methods for Everyday Life. San Francisco: JosseyBass. 